\title{
Antimalarial endoperoxides: synthesis and implications of the mode of action
}

\author{
Constantinos Koutsoupakis, Irene Gialou, Eleni Pavlidou, Sofia Kapetanaki, \\ and Constantinos Varotsis* \\ Department of Chemistry, University of Crete, Heraklion 71409, Crete, Greece \\ E-mail: varotsis@edu.uoc.gr
}

\begin{abstract}
Dedicated to Professor Gerasimos J. Karabatsos on the occasion of his $70^{\text {th }}$ birthday (received 01 Mar 03; accepted 09 Jul 03; published on the web 09 Jul 03)
\end{abstract}

\begin{abstract}
6,7-Dioxabicyclo[3.2.2]non-8-ene 2 and 1-isopropyl-4-methyl-2,3-dioxabicyclo[2.2.2]oct-5-ene (ascaridol) 3 were prepared as simplified, endoperoxide versions of clinically used antimalarial drugs. Fourier transform infrared (FTIR) technique in conjunction with ${ }^{18} \mathrm{O}_{2}$-enriched compound 2 has been applied in probing the bonds of the endoperoxide moiety and the bonds of the rings owing to the presence of the $\mathrm{O}-\mathrm{O}$, the $\mathrm{C}-\mathrm{O}$, the $\mathrm{O}-\mathrm{O}-\mathrm{C}$ as well as the $\mathrm{C}=\mathrm{O}$ modes in the spectrum. The endoperoxide moiety is especially useful in this regard because the homolytic cleavage of the $\mathrm{O}-\mathrm{O}$ bond can be characterized and hence can be used to assess the vibrational properties of the $\mathrm{O}$ - and $\mathrm{C}$-centered radicals and subsequently that of the $\mathrm{C}-\mathrm{C}$ bond cleavage. The cleavage of the $\mathrm{O}-\mathrm{O}$ bond, and the ability to correlate vibrational properties of the reaction products with structural properties of the isolated products suggest that infrared spectroscopy is an appropriate tool to study the mode of action of antimalarial endoperoxides.
\end{abstract}

Keywords: FTIR spectroscopy, ${ }^{18} \mathrm{O}_{2}$ endoperoxide, $\mathrm{O}-\mathrm{O}$ bond cleavage mechanism

\section{Introduction}

Malaria is one of the most widespread parasitic diseases caused by invasion protozoan parasites of the class of Plasmodium into the human body. ${ }^{1}$ It is estimated that there are 240 million people who are chronically affected, and there are 120 million new cases reported every year. ${ }^{2,3}$ There is a general consensus that antimalarial peroxides, both of natural and synthetic origin, kill the Plasmodium parasite through a mode of action that is entirely different from that of the traditional quinoline-based drugs such as quinine and chloroquine. ${ }^{4}$ While the mechanism of action of the antimalarial endoperoxides is not completely understood, there is growing evidence that the initial key step is the reductive cleavage of the $\mathrm{O}-\mathrm{O}$ bond of the endoperoxide moiety, 
leading to oxygen- and then carbon-centered radicals that subsequently cause the biologically relevant damage of the malarial parasite. Artemisinin $\mathbf{1}^{5}$ and its semisynthetic dihydro derivatives posses an endoperoxide function as the essential structural component of their activity. Clinical trials of artemisinin derivatives are now being sponsored by the World Health Organization and clinical studies using suppositories containing water-soluble sodium artesunate have produced striking malarial cure rates. ${ }^{6}$ The extraction and the cost of artemisinin derivatives is a limiting factor to the wide use of these efficient drugs in tropical and subtropical regions, where the malaria is endemic and chloroquine-resistant strains are spreading. Therefore, there is a need for new, low-cost synthetic drugs with pharmacological properties similar to those of artemisinin. Rational design and laboratory synthesis of structurally simpler endoperoxides have led to various peroxide compounds, different from artemisinin, some of which have excellent antimalarial activity.

Several important properties of artemisinin have been determined from studies of simpler trioxane analogs. It has been established by Posner and co-workers that deoxygenation of 1,2,4 trioxanes into corresponding 1,3-dioxolanes occurs via an unzipping-zipping process. ${ }^{7}$ The $\mathrm{Fe}(\mathrm{II})$-induced cleavage of the peroxide bond in trioxane tosylate leads through the $\mathrm{C}-\mathrm{C}$ bond cleavage to a ring-contracted tetrahydrofuran acetal and then produces a stable electophilic tetrahydrofuran aldehyde. On the other hand, the 1,5-H shift process produces stable 4-hydroxy deoxytrioxane as a mixture of two diastereomers. These findings led these authors to conclude that the reduction of the endoperoxide by Fe(II) follows a different mechanistic course leading to different products than the endoperoxide cleavage by non $\mathrm{Fe}(\mathrm{II})$ reducing agents. ${ }^{8}$ Recently, the use of the ${ }^{18} \mathrm{O}_{2}$ enriched trioxane alcohol allowed us to detect the heme $\mathrm{Fe}(\mathrm{IV})=\mathrm{O}$ intermediate in the artemisinin/hemin dimer reaction. ${ }^{9}$

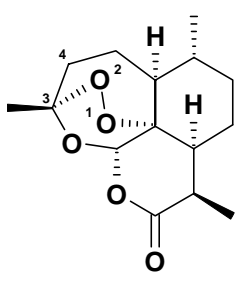

1

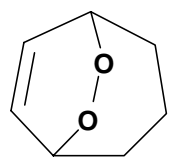

2

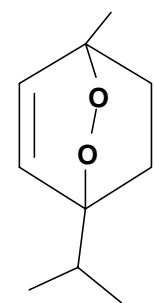

3

6,7-dioxabicyclo[3.2.2.]non-8-ene

The Fourier transform infrared (FTIR) technique has been applied to the study of some 1,2,4trioxanes and has been found to be powerful in probing the bonds of the endoperoxide moiety and the bonds of the rings owing to the presence of the $\mathrm{O}-\mathrm{O}$, the $\mathrm{C}-\mathrm{O}$, the $\mathrm{O}-\mathrm{O}-\mathrm{C}$ as well as the $\mathrm{C}=\mathrm{O}$ modes in the spectrum. The endoperoxide moiety is especially useful in this respect because the homolytic cleavage of the $\mathrm{O}-\mathrm{O}$ bond can be characterized and hence can be used to assess the vibrational properties of the $\mathrm{O}$ - and $\mathrm{C}$-centered radicals, and subsequently that of the 3-C-4-C bond cleavage. In our previous work, ${ }^{10}$ we applied the FTIR approach to further characterize the reactions of artemisinin and its synthetic analog trioxane alcohol with $\mathrm{Fe}(\mathrm{II})$ and 
$\mathrm{Fe}(\mathrm{III})$. Although the $\mathrm{Fe}(\mathrm{III}) /$ artemisinin reaction is slower, we showed that cleavage of the $\mathrm{O}-\mathrm{O}$ bond occurs and the three products formed have vibrational characteristics similar to those found in the products of the $\mathrm{Fe}(\mathrm{II}) /$ artemisinin reaction. The product ratios in the $\mathrm{Fe}(\mathrm{II})$ and $\mathrm{Fe}(\mathrm{III})$ reactions was depended on the oxidation state of the iron and thus on whether the activation follows the 1,5 $\mathrm{H}$-shift or the $\mathrm{C}_{3}-\mathrm{C}_{4}$ cleavage pathway. In the case of the $\mathrm{Fe}(\mathrm{II})$-induced cleavage of trioxane alcohol, three major products were detected and their characteristic $\mathrm{C}=\mathrm{O}$ vibrations are located at 1717 and $1740 \mathrm{~cm}^{-1}$ and that of the hydroxyl (OH) at $3433 \mathrm{~cm}^{-1}$. We also applied laser photolysis FTIR techniques to monitor the FTIR spectra of artemisinin photoproducts, and found that the $\mathrm{O}-\mathrm{O}$ bond is photolabile. The artemisinin photoproducts have vibrational characteristics which are similar to those observed in their corresponding $\mathrm{Fe}(\mathrm{II})$ - and Fe(III)induced reductive cleavage products. From the different product ratios observed in the Feinduced cleavage of the endoperoxide and that in the photolytic cleavage we infer that there is a mechanistic difference between the two processes. These results also provide important links between metabolites and chemical reaction products that have been observed in the antimalarial mode of action of trioxanes. Following our search for novel compounds with high antimalarial activity, in the work presented here compounds $\mathbf{2}$ and $\mathbf{3}$ were prepared and characterized.

\section{Materials and Methods}

Artemisinin 1 (98\%, Aldrich Chemical Company) was used without further purification. 6,7Dioxabicyclo[3.2.2.]non-8-ene 2 and its ${ }^{18} \mathrm{O}-{ }^{18} \mathrm{O}$ labeled analog were synthesized by introducing ${ }^{16} \mathrm{O}_{2}$ (99\%, Messer) and ${ }^{18} \mathrm{O}_{2}$ (97\%, Isotec), respectively, to 1,3-cycloheptadiene (97\%) in the photosensitized oxygenation step. In the ${ }^{18} \mathrm{O}_{2}$ photooxygenation experiment, ${ }^{18} \mathrm{O}_{2}$ gas $(25 \mathrm{~mL})$ was anaerobically transferred to a tightly sealed evacuated flask containing a solution of 1,3cycloheptadiene $(100 \mathrm{mg})$ in dichloromethane $(25 \mathrm{~mL})$ and in the presence of methylene blue sensitizer $(5 \mathrm{mg})$. The whole mixture was placed in an ice bath $\left(0{ }^{\circ} \mathrm{C}\right)$ irradiated with a $500 \mathrm{~W}$ lamp for $25 \mathrm{~min}$. The total yield of 2 was $30 \%$ and the final isotope enrichment was $\sim 70 \%$. In the case of ${ }^{16} \mathrm{O}-{ }^{16} \mathrm{O}$ photooxidation a continuous flow of ${ }^{16} \mathrm{O}_{2}$ was affordable, and the yield approached $100 \%$. Ascaridole 3 was synthesized in a similar way by introducing ${ }^{16} \mathrm{O}_{2}$ to $\alpha$ terpinene ( $85 \%$ ), during the photooxygenation step.

The FTIR spectra were recorded at $293 \mathrm{~K}$ from thin film samples placed on a $\mathrm{AgCl}$ window, at $2 \mathrm{~cm}^{-1}$ spectral resolution with a Bruker Equinox IFS 55 FTIR spectrometer equipped with a liquid nitrogen cooled mercury cadmium telluride (MCT) detector. Typically, 100 scans were recorded and averaged for each spectrum. 


\section{Results and Discussion}

The FTIR spectra presented here and the frequencies of the modes are fully consistent with earlier studies of artemisinin, and with the vibrational data reported for some 1,2,4 trioxanes by Jefford and co-workers. ${ }^{11}$ The FTIR modes in the $700-1200 \mathrm{~cm}^{-1}$ range have been shown to be sensitive indicators to the $\mathrm{O}-\mathrm{O}$ and $\mathrm{C}-\mathrm{O}$ modes of the $\mathrm{O}-\mathrm{O}-\mathrm{C}$ unit, and at $1735 \mathrm{~cm}^{-1}$ to $\delta$-lactone carbonyl $v(\mathrm{C}=\mathrm{O})$ mode. Figures $1 \mathrm{a}$ and $1 \mathrm{~b}$ show the FTIR spectra of artemisinin 1 and ascaridole 3, respectively. The principal bands seen in Figure 1a are assigned in analogy to those vibrations found in other 1,2,4-trioxanes. ${ }^{11}$ The $\mathrm{O}-\mathrm{O}$ stretching and $\mathrm{C}-\mathrm{O}$ stretching modes and bending modes of the $\mathrm{C}-\mathrm{O}-\mathrm{O}-\mathrm{C}$ moiety are located at 723, 831, 883 and $1114 \mathrm{~cm}^{-1}$, respectively; the $\mathrm{C}=\mathrm{O}$ mode of $\delta$-lactone at $1735 \mathrm{~cm}^{-1}$. Based on ${ }^{18} \mathrm{O}_{2}$ enriched ascaridole we have assigned the $730 \mathrm{~cm}^{-1}$ mode to the $\mathrm{O}-\mathrm{O}$ stretching. Figures $2 \mathrm{a}$ and $2 \mathrm{~b}$ show the FTIR spectra of ${ }^{16} \mathrm{O}_{2-}$ and ${ }^{18} \mathrm{O}_{2}$-enriched compound 2, respectively. These data illustrate that the modes located at 718/701, $798 / 786$ and 896/884 $\mathrm{cm}^{-1}$ arise from the O-O stretching of compound 2.

Computational studies on the radical intermediates will enable us to reveal the details of their structures, stability, and reactions. Such information on the radical transfer-ring process will be helpful in understanding the bio-action phenomena of compounds 2 and 3. Figure 3 depicts the calculated FTIR spectrum of compound 2 at the HF/6-311++G** level. We expect these theoretical calculations to form the basis for the details of the potential energy surfaces of both the intramolecular 1,5-H atom shift and the homolytic 3-C-4-C cleavage process. This way we will be able to address the following questions: (1) Is there a high energy barrier to block the intramolecular 1,5-H shift? (2) Is it possible to detect experimentally the O-centered radicals? Experiments to address these questions are in progress in our laboratory.
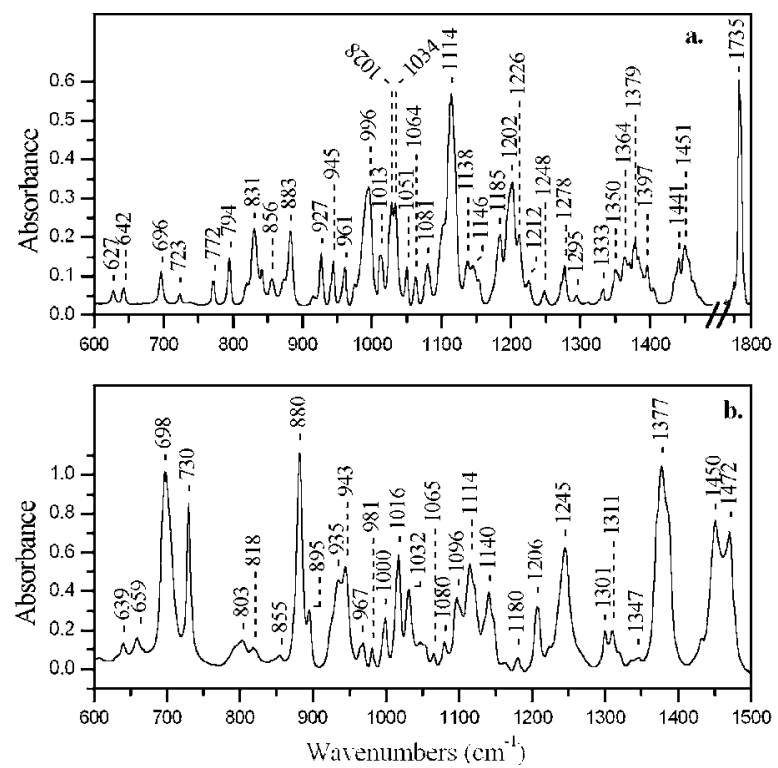

Figure 1. FTIR spectra of artemisinin (a) and ascaridole (b). The spectral resolution was $2 \mathrm{~cm}^{-1}$ and 100 scans were recorded and averaged. 


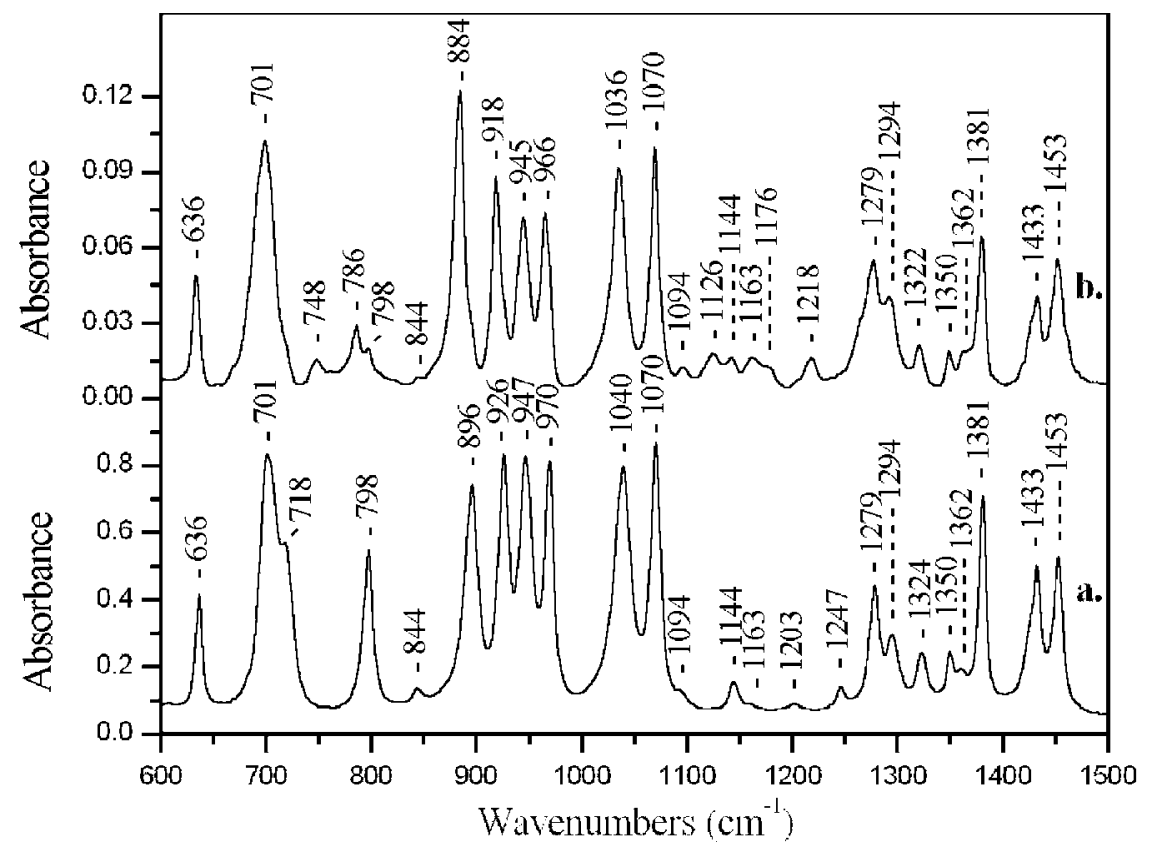

Figure 2. FTIR spectra of 6,7-dioxabicyclo[3.2.2.]non-8-ene 2 (a) and its ${ }^{18} \mathrm{O}-{ }^{18} \mathrm{O}$ labeled analog (b). The spectral resolution is $2 \mathrm{~cm}^{-1}, 100$ scans were recorded and averaged.

In an effort to understand the progression of the intermediates in the $\mathrm{O}-\mathrm{O}$ cleavage of artemisinin, we present a reaction scheme for artemisinin (Scheme 1). The structures of the intermediates and those of the final products were taken from our data and the literature. Although $\mathrm{O}$ - and $\mathrm{C}$-centered radicals are depicted in Scheme 1, there is no evidence for the build-up of such intermediates in our previous measurements. The characterization of the Ocentered radicals produced in the cleavage of the $\mathrm{O}-\mathrm{O}$ bond as well as the detection of $\mathrm{C}$ centered radicals, formed either through a $1,5-\mathrm{H}$ shift or by homolytic 3-C-4-C bond cleavage remains problematic, because they exhibit very short lifetimes $\left(10^{-6}-10^{-9} \mathrm{~s}\right)$. However, it has been shown in several 1,2,4-trioxanes like artemisinin, that only the pathways involving the 4-C radical intermediate (resulting from 1,5-H shift) is important for high antimalarial activity. ${ }^{12,13}$ Recently, Gu et al. ${ }^{14}$ in a DFT study showed that the rate constant for the classical 1,5-H shift is $1.3 \times 10^{8} \mathrm{~s}^{-1}$ and $2.9 \times 10^{-35} \mathrm{~s}^{-1}$ at $298 \mathrm{~K}$ and $30 \mathrm{~K}$ respectively. These authors concluded that the corresponding O-centered radical is detectable experimentally at low temperature. Moreover, they calculated the 3-C-4-C bond cleavage rate to be $1.9 \times 10^{8} \mathrm{~s}^{-1}$ and $1.2 \times 10^{-33} \mathrm{~s}^{-1}$ at $298 \mathrm{~K}$ and $30 \mathrm{~K}$, respectively, and they reported that the C-centered radical is $5.2 \mathrm{kcal} / \mathrm{mol}$ more stable than the O-centered radical. Since there is experimental evidence both for the formation of a secondary 4-C radical and of an unstable epoxide by $\mathrm{Wu}$ et al. $^{15}$ and for the formation of a primary4-C radical, ${ }^{16}$ their structures were used in Scheme 1. The epoxide was characterized by its IR spectrum giving rise to $v(\mathrm{OH})$ and $y(\mathrm{C}=\mathrm{O})$ at 3500 and $1728 \mathrm{~cm}^{-1}$, respectively. 


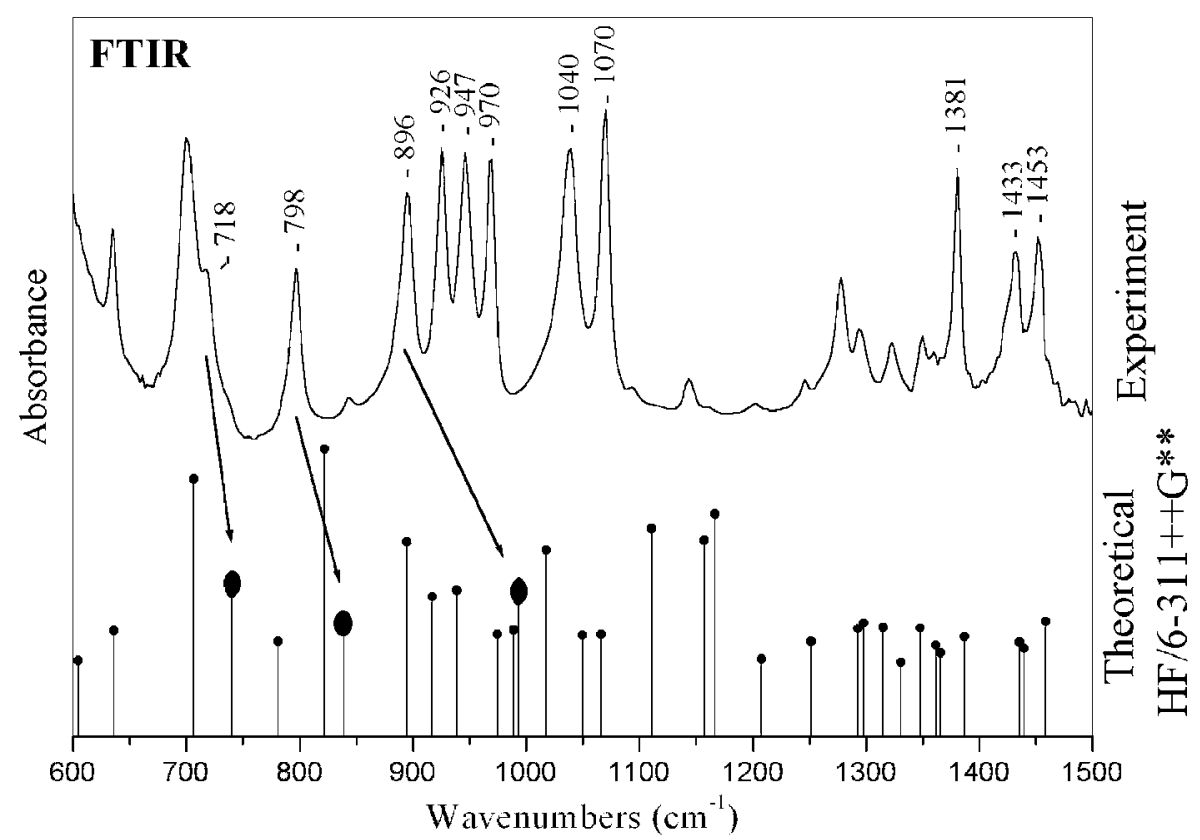

Figure 3. Comparison between the experimental and the theoretical FTIR spectrum of 6,7dioxabicyclo[3.2.2.]non-8-ene 2. The three marked modes in the calculated spectrum correspond to the $\mathrm{O}-\mathrm{O}$ stretching vibration of the endoperoxide bridge, according to the molecular orbital analysis.

In the reaction scheme depicted in Figure 4, two separate pathways are indicated for the decay of the primary $\mathrm{O}$-centered radicals. In the first pathway, if iron associates with $\mathrm{O}_{1}$, then compound 5 is formed which is converted, via the $\mathrm{C}_{3}-\mathrm{C}_{4}$ scission, to the primary $\mathrm{C}_{4}$ radical compound 7. The latter compound is converted to compound 10. On the other hand, if iron associates with $\mathrm{O}_{2}$, then through the 1,5-H shift compound 4 is converted to the secondary $\mathrm{C}_{4}$ radical compound $\mathbf{6}$. The later compound can be either converted to the unstable epoxide $\mathbf{9}$, with the concomitant formation of $\mathrm{Fe}(\mathrm{IV})=\mathrm{O}$ or to the stable compound $\mathbf{8}$ and the formation of $\mathrm{Fe}(\mathrm{III})-\mathrm{OH}$. Compound 9 can be further converted to the final product 11. Under all experimental conditions we used, there is no evidence for the build-up of either a secondary radical or of the unstable epoxide, due to the absence of a peak at $1728 \mathrm{~cm}^{-1}$, thus we assume that their lifetimes are very short. In the case of $\mathrm{Fe}(\mathrm{II})$ reaction, the ratio of the $\mathrm{I}\left(1755 \mathrm{~cm}^{-1}\right.$, compound 8)/I(1717 $\mathrm{cm}^{-1}$, compound 10) is 1.2 while in the photolysis products is 2.8 . Consequently, under the conditions in which the O-O bond is cleaved photolytically, and in the absence of bound Fe to neither of the oxygens of the endoperoxide bridge, the dominant pathway is that in which compound $\mathbf{8}$ is formed. 

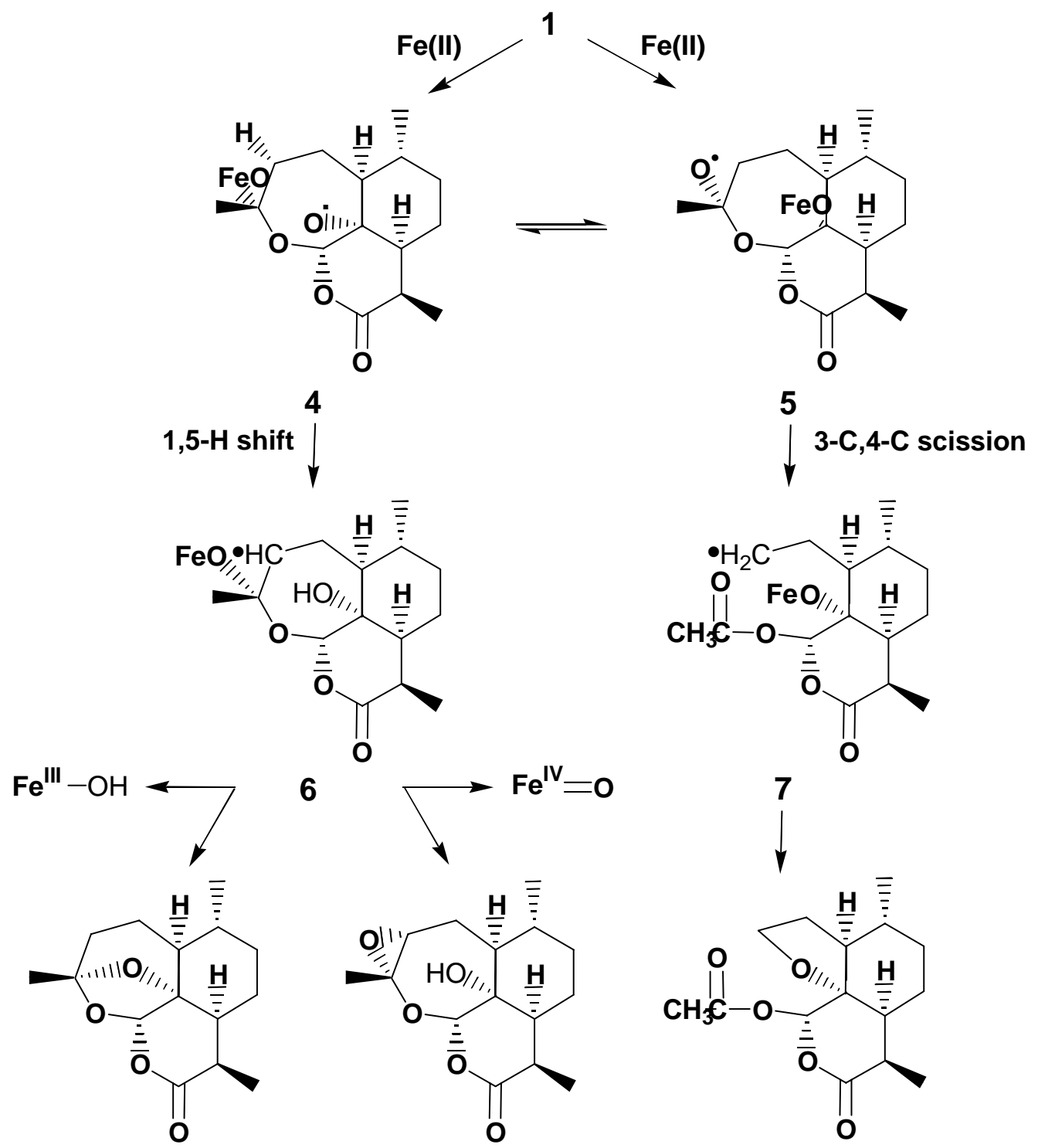

8
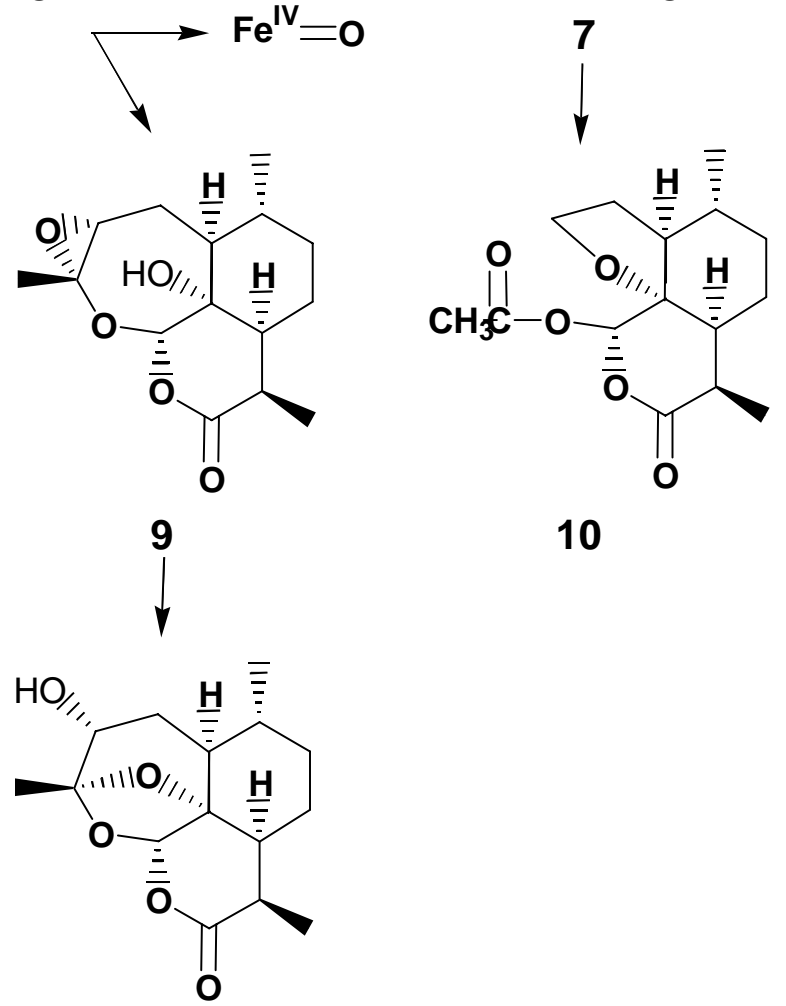

10

11

Scheme 1. Proposed mechanism for the Fe(II)-induced activation of artemisinin 1. 
The reactions of compounds 2 and 3, with both heme and non heme $\mathrm{Fe}$ (II) and Fe(III), and the comparison with the well-studied 1,2,4 trioxanes will contribute to a better molecular basis for rational design of new synthetic endoperoxide-containing antimalarial drugs. In addition, the photolytic cleavage of the O-O moiety will be monitored through the FTIR spectroscopy and properties about the nature of the bond and the way it affects the biological activity of the drugs will be revealed. These studies will ultimately lead to flow time-resolved step-scan FTIR experiments where the detection and the evolution of the radical intermediates will definitely resolve the reaction mechanism. ${ }^{17}$ Finally, theoretical calculations focused especially on the energy barriers raised between the two allowed pathways will address some important details on the intramolecular 1,5- $\mathrm{H}$ shift process, as well as the structural details of the $\mathrm{O}$ - and C-centered radicals.

\section{References}

1. Ridley, R. G. Science 1999, 285, 1502.

2. Miller, L. H.; Greenwood, B. Science 2002, 298, 121.

3. Sachs, J. D. Science 2002, 298, 122.

4. Wellems, T. E. Science 2002, 298, 124.

5. Klayman, D. L. Science 1985, 228, 1049.

6. Ridley, R. G. Nature 2002, 415, 686.

7. Cumming, J. N.; Ploypradith, P.; Posner, G. H. Adv. Pharmacol. 1997, 37, 253.

8. Posner, G. H.; Oh, C. H. J. Am. Chem. Soc. 1992, 114, 8328.

9. Kapetanaki, S.; Varotsis, C. FEBS Lett. 2000, 474, 238.

10. Kapetanaki, S.; Varotsis, C. J. Med. Chem. 2001, 44, 3150.

11. Monhaupt, M.; Hagemann, H.; Perler, J.-P.; Bill, H.; Boukouvalas, J.; Rossier, J.-C.; Jefford, C. W. Helv. Chim. Acta 1988, 71, 992.

12. Posner, G. H.; Wang, D.; Cumming, J. N.; Oh, C. H.; French, A. N.; Bodley, A. L.; Shapiro, T. J. Med. Chem. 1995, 38, 2273.

13. Posner, G. H.; Oh, C. H.; Wang, D.; Gerena, L.; Milhous, W. K.; Meshnick, S. R.; Asawamahasadka, W. J. Med. Chem. 1994, 37, 1256.

14. Gu, J.; Chen, K.; Jiang, H.; Leszczynski, J. J. Phys. Chem. A 1999, 103, 9364.

15. Wu, W.-M.; Wu, Y.; Wu, Y.-L.; Yao, Z.-J.; Zhou, C.-M.; Li, Y.; Shan, F. J. Am. Chem. Soc. 1998, 120, 3316.

16. Butler, A. R.; Gilbert, B. C.; Hulme, P.; Irvine, L. R.; Renton, L.; Whitwood, A. C. Free Radical Res. 1998, 28, 471.

17. Wu, Y. Acc. Chem. Res. 2002, 35, 255. 